\section{O "MACHO NORDESTINO" EM FORMAÇÃO: SEXUALIDADE E RELAÇÕES DE GÊNERO ENTRE ADOLESCENTES}

\author{
The "northeastern male" in formative years - sexuality and \\ gender relations among teenagers
}

El "hombre del noreste" en formación: sexualidad y relaciones de género entre adolescentes

\section{RESUMO}

Objetivo: Analisar a sexualidade e as relações de gênero sob a ótica de adolescentes. Métodos: Estudo qualitativo realizado com dez adolescentes de escolas públicas de Fortaleza, CE. Os dados foram coletados no período de maio a junho de 2012 usando entrevistas semiestruturadas e analisados através da Análise do Discurso. Resultados: Os adolescentes trouxeram elementos discursivos que refletem os tabus que os cercam sobre a sexualidade e a marcada exigência de um comportamento estereotipado segundo os padrões regionais. A necessidade de autoafirmação masculina, a submissão feminina ante os desejos masculinos, a responsabilidade da mulher pela reprodução e o preconceito velado em relação à homossexualidade foram comuns nos discursos dos participantes, como uma extensão de suas realidades familiar e social. Esses padrões espelham um modelo hierárquico de relação de gênero que expõe homens e mulheres a situações de vulnerabilidade eternizadas por fatores socioculturais e que iniciam sua afirmação no período da adolescência. Conclusão: Desse modo, torna-se imperioso trabalhar as questões de gênero com esse grupo, mediante a exposição de novas perspectivas, visando mudanças de atitudes e convicções.

Descritores: Adolescente; Sexualidade; Relações de Gênero; Vulnerabilidade em Saúde.

\section{ABSTRACT}

Objective: To analyze sexuality and gender relations from the perspective of adolescents. Methods: Qualitative study carried out with ten teenagers from public schools of Fortaleza, CE. Data was collected from May to June 2012, with use of semi-structured interviews and was analyzed through Discourse Analysis. Results: The adolescents brought discursive elements that reflect the taboos that surround them about sexuality and the marked requirement of a stereotyped behavior in accordance with the regional standards. The need for male assertiveness, female submission before the male desires, the woman's responsibility for the reproduction, and veiled prejudice towards homosexuality were common in the speeches of the participants, as an extension of their family and social realities. Such patterns reflect a hierarchical model of gender relations that exposes men and women to situations of vulnerability perpetuated by sociocultural factors and initiate their affirmation during adolescence. Conclusion: Thus, it is imperative to work on gender issues in this group, through the exposure to new perspectives, with the aim of changing attitudes and beliefs.

Descriptors: Adolescent; Sexuality; Gender Relations; Vulnerability.
Artigo Original
1) Universidade de Fortaleza - UNIFOR Fortaleza (CE) - Brasil
Recebido em: 05/08/2015 Revisado em: 28/10/2015 Aceito em: 07/11/2015 


\section{RESUMEN}

Objetivo: Analizar la sexualidad y las relaciones de género a partir de la opinión de los adolescentes. Métodos: Estudio cualitativo realizado con diez adolescentes de escuelas públicas de Fortaleza, CE. Los datos fueron recogidos en el periodo entre mayo y junio de 2012 con entrevistas semiestructuradas y analizados a través del Análisis del Discurso. Resultados: Los adolescentes trajeron elementos del discurso que reflejan los tabúes sexuales y la fuerte exigencia de una conducta estereotipada según los patrones regionales. La necesidad de la autoafirmación masculina, la sumisión femenina delante los deseos masculinos, la responsabilidad de la mujer por la reproducción y el perjuicio respecto la homosexualidad fueron comunes en los discursos de los participantes como una extensión de sus realidades familiar y social. Eses patrones reflejan un modelo jerárquico de la relación de género que expone los hombres y las mujeres a situaciones de vulnerabilidad eternizadas por factores socioculturales y que comienza su afirmación en la adolescencia. Conclusión: De esa manera, se hace importante trabajar las cuestiones de género con ese grupo mediante la exposición de nuevas perspectivas con el objetivo de cambios de actitudes y convicciones.

Descriptores: Adolescente; Sexualidad; Relaciones Interpersonales; Vulnerabilidad en Salud.

\section{INTRODUÇÃO}

A sexualidade é uma elaboração social que, ao longo da história, sempre foi objeto de preocupação moral e submetida a valores e ideologias predominantes na sociedade ${ }^{(1,2)}$. São muitos os problemas de saúde pública que se relacionam diretamente com o estudo da sexualidade, como a expansão das Doenças Sexualmente Transmissíveis (DST) e do número de gravidezes inoportunas na adolescência. Não são, entretanto, menos graves aqueles que recebem sua influência indireta, embora marcante, como as violências relacionadas às questões de gênero ${ }^{(3,4)}$.

Embora essas relações atuem em todas as fases da vida, é na adolescência que os valores tidos como "normais" são introjetados, incluindo os modos de relação entre os gêneros ${ }^{(5)}$. Essas relações orientam o estabelecimento de hierarquias e conflitos que ultrapassam requisitos biológicos, produzindo vulnerabilidades que tendem a perdurar além da adolescência.

Existem quatro elementos relacionados à construção da identidade de gênero: os símbolos culturais, os conceitos normativos, as organizações e instituições, e a identidade subjetiva, de modo que a identidade cultural é um constructo produto de uma série de discursos que circulam na sociedade ${ }^{(6)}$.

No Nordeste, o estabelecimento das relações de gênero adquire um aspecto muito singular em virtude das características atribuídas ao nordestino e por ele introjetadas na formação de sua identidade cultural. Essa região é marcada por um cenário de violência de gênero contra a mulher, vinculada às relações de poder, decorrentes do lugar ocupado culturalmente pelo sexo masculino. As mulheres nordestinas sofreram mais agressões físicas no ambiente doméstico quando comparadas às de outras regiões do país ${ }^{(7)}$. Outro estudo estima que, entre 2009 e 2011, o Brasil registrou 16,9 mil mortes de mulheres por conflito de gênero, especialmente em casos de agressão perpetrada por parceiros íntimos, sendo o Nordeste a região com as piores taxas $(6,9 \text { casos por } 100 \text { mil mulheres })^{(8)}$. Essas constatações reforçam a hegemonia masculina nas relações de gênero e convoca a se fazer reflexões sobre os papéis feminino e masculino socialmente constituídos no contexto estudado.

Ao salientar o papel do poder nas significações e identidades culturais, esse campo abre espaço para compreender que a sexualidade, longe de ser um fenômeno natural, é profundamente suscetível às influências sociais e culturais. A história da concepção de corpo e sexualidade configura-se na história dos sistemas de valores fundamentais em cada sociedade ${ }^{(9)}$.

Nessa perspectiva, torna-se importante estudar as relações de gênero para além do seu modus operandi já estabelecido. É preciso compreender como se constroem e se firmam nas personalidades ainda em fase de estruturação, ou seja, na adolescência. A relevância deste estudo é maior em uma região onde "ser macho" é um imperativo e onde esses adolescentes vivenciam a concepção binária "homem versus mulher", que vai servir de base para a constituição das subjetividades masculina e feminina, em suas diversas formas.

Diante desse contexto, indaga-se: quais as concepções do adolescente sobre sexualidade e as relações de gênero? Desse modo, este artigo objetiva analisar a sexualidade e as relações de gênero sob a ótica de adolescentes.

\section{MÉTODOS}

Estudo qualitativo realizado em duas escolas públicas da Secretaria Regional VI (SERVI) de Fortaleza, Ceará. A SER VI é a maior em população e ofertas de serviços públicos de saúde entre as regionais do município.

Participaram da pesquisa dez adolescentes entre $14 \mathrm{e}$ 18 anos de idade, regularmente matriculados nas referidas escolas, cujos pais assinaram o Termo de Consentimento Livre e Esclarecido (TCLE). Os adolescentes foram selecionados durante visitas preliminares de reconhecimento do campo. Buscou-se selecionar sujeitos com voz ativa entre seus pares ou que exercessem uma posição de liderança nos grupos. Desse modo, a escolha dos informantes assumiu um caráter intencional e teórico, sendo eleitos por sua relevância 
em aprofundar e explorar a questão da pesquisa, e não por representatividade estatística. A saturação foi utilizada para o fechamento da amostra teórica ${ }^{(10)}$.

Os dados foram coletados no período de maio a junho de 2012, usando entrevistas semiestruturadas, cujas questões norteadoras tratavam de sexualidade, mudanças no corpo durante a adolescência e relações de gênero. As entrevistas foram transcritas na íntegra, respeitando-se entonação, interjeições e interrupções; sendo codificadas com a letra A e numeradas de 1 a 10, como forma de preservar o anonimato dos participantes. Antes da entrevista, cada participante respondeu a um questionário que abordava aspectos sociodemográficos, com as seguintes variáveis: sexo biológico, idade, série escolar, religião, participação em atividades religiosas e sexarca.

As transcrições foram trabalhadas integrando o objetivo da pesquisa, as concepções teórico-conceituais e o conhecimento prévio do campo empírico. As análises do material empírico se fundamentaram no campo denominado Estudos Culturais, em suas vertentes pós-estruturalistas ${ }^{(11)}$.

Neste estudo, entende-se a sexualidade, as relações de gênero e a adolescência como elaborações culturais produzidas nos acontecimentos históricos e culturais. Esse campo teórico oferece um panorama favorável para a Análise doDiscurso, método analítico que explora os processos sociais que os discursos (re)produzem, bem como as relações de conhecimento e poder que os perpassam. Considerando que as performances de gênero relacionam-se diretamente com o poder e a ideologia que moldam a realidade social ${ }^{(12,13)}$, e que toda prática social tem condições culturais ou discursivas de existência ${ }^{(14)}$, encontrou-se um foco no discurso como um processo que se dá sobre a língua, com base no encontro entre uma memória - interdiscurso - e um acontecimento - o próprio movimento da produção material da vida ${ }^{(15-18)}$, descortinando um panorama favorável à Análise do Discurso - aqui utilizada segundo a escola francesa ${ }^{(19,20)}$ - que articula o linguístico ao sócio-histórico e ao ideológico, colocando a linguagem na relação com os modos de produção social. A partir dessa análise, emergiram as seguintes categorias: " $E u$ sou é macho": a sexualidade para os meninos; Entre o recato e a malícia: a sexualidade para as meninas; "O papel do homem é tentar e o da mulher é resistir": o estabelecimento de papéis sociais baseados no gênero; Preconceito ou tolerância: a identidade de gênero para os adolescentes.

O projeto desta pesquisa foi aprovado pelo Comitê de Ética e Pesquisa da Universidade de Fortaleza, sob o $\mathrm{n}^{\mathrm{o}}$ $435 / 2011$.

\section{RESULTADOS E DISCUSSÃO}

A seguir, serão apresentados os dados de identificação dos entrevistados para, logo após, serem apresentadas as categorias de análise que emergiram do estudo.
Dos participantes, quatro eram homens e seis mulheres; seis católicos, dos quais quatro declararam participar das atividades da igreja, e quatro evangélicos, todos praticantes; três estavam namorando no momento (dois homens e uma mulher) e seis já haviam tido algum intercurso sexual (três homens e três mulheres).

As duas primeiras categorias temáticas tratam da percepção da sexualidade para meninos e meninas.

\section{"Eu sou é macho": a sexualidade para os meninos}

Entre os meninos, observou-se, nesta categoria, uma mudança de comportamento no decorrer do discurso. Inicialmente, mostraram-se cautelosos, demonstrando maior espontaneidade ao final das entrevistas. Os adolescentes que relataram intercurso sexual prévio referiram dúvidas quanto ao início de sua vida sexual.

"É dificil perguntar, é chato. A gente não pode perguntar para a mãe porque ela mata a gente. Pela minha mãe, eu virava padre. Ela odeia minha namorada porque diz que moça direita não sai de noite sozinha com o namorado. Meu pai só diz que é para eu botar é quente. Aí fica ruim. A sorte é que eu puxei ao meu pai. O cabra era danado quando era novo." (A4)

"Minha primeira vez foi complexa. Porque a menina achava que eu já tinha experiência, mas eu não tinha. Até fui ver uns vídeos na internet para não fazer feio. A sorte é que ela era virgem. Mas eu fiz direitinho. Eu sou é macho." (A7)

As relações de gênero permeiam todo o tecido social $^{(21,22)}$, sendo primordiais para entender as relações de poder estabelecidas entre homens e mulheres na sociedade e as vulnerabilidades a que os gêneros estão expostos. $\mathrm{O}$ conceito de gênero consolidado nessa expressão pode ser entendido como o processo pelo qual a sociedade classifica e atribui valores e normas, estabelecendo, assim, as diferenças e hierarquias sexuais, delimitando o que seriam papéis masculinos e femininos. Representa a aceitação de que a masculinidade e a feminilidade transcendem a questão da anatomia, remetendo à permanente interdependência do biológico em relação ao psicossocial em cada cultura específica ${ }^{(23)}$.

Focando especificamente nos adolescentes, sabe-se que eles formam um seleto grupo etário que passa por intensas mudanças nos quesitos biológicos, psíquicos e sociais. É uma etapa cheia de conflitos pessoais e interpessoais, em que os adolescentes incorporam influências culturais que irão repercutir diretamente nos seus comportamentos e atitudes ante as relações de gênero. Com efeito, compreender o fenômeno da sexualidade nesse grupo a partir das relações de gênero permite situá-los no contexto social, o que implica ir além das questões biológicas e epidemiológicas. 
O que não está dito pelos discursos, mas está atrelado a estes, é o reconhecimento do círculo vicioso que perpetua as relações hierarquizadas de gênero. Se, entretanto, por um lado, essa hierarquização da sexualidade situa as meninas em condição de vulnerabilidade, tampouco é fácil para os meninos se estabelecerem. "O cabra (pai) era danado", e o filho quer ser igual ao pai. Essa expressão traduz a exigência social do papel masculino em relação à sua sexualidade - o papel de dominador, de "macho", que não é socialmente apenas esperado, mas imposto por seu meio. $\mathrm{O}$ pai não esclarece as dúvidas do adolescente, apenas o orienta a "botar é quente", expressão que pode ser traduzida não em estabelecer uma vida sexual ativa, mas em fazer com que suas proezas sejam reconhecidas por seus pares, de modo a legitimar sua masculinidade, caracterizada pela violência de seus impulsos e por sua virilidade. Assim, o rapaz precisa ter um bom desempenho sexual diante de sua parceira. Ser virgem é motivo de vergonha. Foi-lhe culturalmente exigido que sua potência fosse demonstrada e conhecida, para que lhe coubesse a alcunha de "macho".

As explicações acerca das diferenças no início da vida sexual entre homens e mulheres baseiam-se no fato de que as normas e expectativas sociais em relação à idade e às circunstâncias adequadas para as primeiras práticas sexuais variam conforme o sexo. Se, para a menina, ao mesmo tempo em que existe o desejo de se descobrir, impõe-se a necessidade de se $\operatorname{preservar}^{(3)}$, para o menino, há uma cobrança social para o início precoce de sua vida sexual ativa $^{(24)}$. Essa atitude, que se inicia na adolescência, tende a perdurar pelas demais fases da vida, situando os meninos e homens em estado de vulnerabilidade no que tange aos cuidados com a saúde e à maior exposição à violência ${ }^{(25)}$.

$\mathrm{O}$ discurso de um dos adolescentes evidencia que os padrões estereotipados de gêneros são incorporados pelas próprias mulheres. Afinal, homens machistas são criados por mulheres. Por um lado, é difícil para a mãe aceitar a iniciação sexual do filho. Por outro, ela o redime da responsabilidade sobre qualquer consequência negativa da vida sexual - a "culpa" é da namorada. Em uma relação de gênero hierarquizada, a mulher é inculpada pelas próprias mulheres inseridas no sistema. A hegemonia masculina é sustentada por um vasto segmento de homens que usufrui de seus benefícios, mas também por mulheres que a concedem.

Se, por um lado, na experiência sexual masculina, o desempenho sexual é visto como um ganho, sustentando o poder da masculinidade, de outra parte, a atitude pode ser decididamente romântica, caso em que o homem busca se entregar no momento certo e à parceira certa ${ }^{(3)}$.

"Não sei se vou casar virgem. Acho que não. Mas também não quero sair por aí fazendo sexo. Acho que vou acabar encontrando uma menina boa. Minha mãe diz que tem que ser da igreja. Mas, eu acho que dá para esperar a menina certa, não sou bicho para não me segurar." (A6)

No primeiro momento, o rapaz parece desvinculado das exigências sociais em relação à sexualidade. Uma análise atenta, entretanto, demonstra que ele está tão assujeitado quanto seus colegas, apenas a ideologia dominante é diferente. Esse adolescente demonstra um grande controle por parte de sua mãe sobre sua vida sexual. É a mãe quem determina sua possível parceira. É a igreja frequentada pela mãe que garante a ela os atributos necessários. Mais uma vez, percebem-se as relações hierarquizadas de gênero perpetuadas pelas próprias mulheres.

\section{Entre o recato e a malícia: a sexualidade para as meninas}

Ao contrário dos meninos, esta categoria evidencia que as adolescentes mostraram-se tensas, utilizando subterfúgios e somente pronunciando a palavra "sexo" se a resposta a exigisse, demonstrando uma atitude de submissão ante a própria sexualidade.

"Eu acho que tem que ensinar a pessoa a diferenciar o agir de uma pessoa durante o ato. Entender praticamente e saber praticar, e não levar só para os lados maliciosos. Porque tem os lados bondosos [...]. A pessoa tem que saber o verdadeiro significado disso, que não é só a malicia." (A9)

Essa adolescente de 15 anos, evangélica, associou o termo "malícia" como oposição à "bondade". A sexualidade é produto de forças sociais e históricas ${ }^{(1)}$. A sociedade e a cultura é que designam se determinadas práticas sexuais são apropriadas ou não, morais ou imorais, saudáveis ou doentias. Sobretudo com a expansão do cristianismo, nos séculos IV e V, o sexo passou a ser algo que era preciso examinar, vigiar e confessar. Assim, quaisquer carícias que não levam ao ato sexual na sua forma "legítima" - para fins reprodutivos - figuram como pecados ${ }^{(1)}$.

Dessa forma, a participante em questão incorporou todas as concepções sobre sexo como pecado que lhe foram transmitidas por sua família. As normas de comportamento sexual the exigem recato, relegando aos comportamentos "maliciosos" um caráter pejorativo e socialmente inaceitável.

Enquanto algumas meninas valorizam o recato, outras demonstram que existe uma pressão para o inicio da vida sexual e para a adequação ao comportamento de uma sociedade de consumo, na qual o sensual e o sexual são apenas mais um produto.

"Ninguém pode obrigar ninguém a nada só porque todo mundo faz. Se todo mundo pular do apartamento, eu não vou pular. Mas o pessoal acha que sabe tudo. Eu acho que 
deveria ter aula de educação sexual para a gente discutir o assunto e todo mundo poder se expressar." (A8)

A adolescente demonstrou estar em conflito com seus pares por tomar uma decisão destoante a respeito do início de sua vida sexual. Para algo "não ser", antes ele tem que "ser". Assim, ao reiterar não ter vergonha, a jovem demonstra que a virgindade é julgada negativamente por seus colegas. Seu comportamento difere do seu grupo social e isso a aflige, a faz desejar um lugar para se expressar, sem julgamento, com a proteção de um tutor, aqui representado pelo professor de educação sexual. Geralmente, há uma forte tendência dos adolescentes a quererem se afirmar dentro do grupo de amigos, por conta da insegurança típica da idade e da necessidade de aceitação ${ }^{(5)}$. Essa aluna em particular quer ser aceita, mas não quer ser obrigada a ferir princípios que internalizou em troca dessa aceitação. Daí a angústia "não dita", mas exposta em seu discurso.

O ser humano, contudo, é um ser social, de modo que a percepção do(a)s adolescentes sobre sua sexualidade perpassa e é atravessada por suas ideias pré-concebidas acerca dos papéis sociais dos gêneros.

\section{"O papel do homem é tentar e o da mulher é resistir": o estabelecimento de papéis sociais baseados no gênero}

Nesta categoria, percebe-se uma contradição pelos discursos já expostos. Enquanto algumas adolescentes demonstram que, mesmo nos tempos contemporâneos, o recato feminino faz parte do comportamento esperado de uma "moça direita", outros discursos demonstram uma realidade em que a sexarca é exigida pelos pares para a aceitação no grupo. Como explicar esses comportamentos femininos diametricamente opostos ante os aspectos socioculturais que os influenciam? Seria uma conquista feminina? Uma liberação de séculos de silêncio em relação aos desejos e anseios sexuais?

As exigências da atual sociedade de consumo fazem emergir valores que se produzem e se reproduzem em grande velocidade, ensejando um sistema de referência e de signos desconexos, fragmentados e, portanto, descartáveis, que aparecem nos discursos dos adolescentes.

"Eu amo minha namorada de verdade. Mas ela é cheia de coisa, e eu sou homem. Meu pai diz que o papel do homem é tentar, e o da mulher é resistir. Enquanto ela resiste, tem um bocado de doidinha para suprir minhas necessidades." (A4)

"Para ser sincero, eu até queria uma namorada. Mas enquanto eu não arrumo uma, eu vou ficando. Tem um bocado de menina bem gostosinha." (A5)

"Usa um short daqueles e quer pagar de virgem para cima de mim. Eu sou é macho! Se bobear, eu boto para dentro." (A7)
Os adolescentes "ficam", estabelecem relacionamentos fugazes baseados na forma física da parceira descartável, que basta ser "gostosinha". O culto ao corpo e à beleza surge como novos valores definidores das relações de gênero. Acompanham-se, cotidianamente, por meio da mídia, a superexposição da sensualidade e a erotização do corpo, que a princípio poderiam ser aceitas como um avanço ou conquista por parte das mulheres. Verifica-se, no entanto, que a sociedade se apropria dessa conquista, empobrecendo e vulgarizando a imagem feminina.

Em um mundo globalizado, a produção do ser feminino e do ser masculino nordestino responde a um projeto de sociedade atual de consumo, de valores globais. Esse homem globalizado, entretanto, não abandonou a consciência do "ser nordestino", do "cabra macho" e viril. Afinal, um "macho" de verdade "bota para dentro". A "mulher de respeito" deve "resistir" às investidas do namorado.

Os discursos das adolescentes demonstraram uma bipolaridade expressa por dois perfis de comportamento feminino antagônicos, refletindo a clássica dicotomia entre os principais estereótipos femininos - "Maria, mãe de Jesus" e a"prostituta Maria Madalena".

"Tem menina que provoca mesmo, se atira para cima dos meninos. Eu acho feio. Os meninos nem respeitam elas e nem dá para respeitar. Quem quer respeito se dá o respeito." (A3).

Mais uma vez, nota-se que as próprias mulheres absolvem os homens dos "pecados" sexuais, considerados naturais ante a virilidade que é esperada do sexo masculino. A adolescente, em sua fala, chega a utilizar gestos e expressões pueris, numa tentativa de ocultação da própria sexualidade - ela "acha feio" o comportamento das colegas.

Discursos anteriores, entretanto, demonstraram que o meio pode exigir da menina/mulher a exposição da sua sensualidade. Quando a mulher, porém, apropria-se de sua sexualidade, é inculpada por seu comportamento, por não se dar o respeito. Como explicar essas exigências sociais destoantes?

Numa sociedade de consumo, na qual o sexo é exposto como um de seus objetos, é importante compreender que expor a sexualidade não significa apropriar-se dela. A superexposição do corpo e a valorização do sexual escondem, atrás de uma fachada de liberalismo, uma sujeição do feminino à satisfação do desejo masculino, desconsiderando os reais desejos e vontades das mulheres.

"Eu já fiquei, sim, uma vez. Para ser sincera, é estranho. Mas estava todo mundo curtindo a festa e o menino estava querendo. Ele investiu forte. E todo mundo botou pilha. E ai foi." (A1)

"As meninas querem fazer tudo, porque se não fizer 
(sic), o namorado deixa. Mas não se cuidam, esquecem de tomar os comprimidos, muitas vezes não tomam [...]. Igual [a] uma amiga minha, que esconde da mãe e não tem dinheiro para comprar." (A8)

A primeira adolescente cedeu às pressões do meio para satisfazer o desejo do rapaz, que "investiu forte", aceitando que esse "investimento" baste para justificar seu mal-estar e "estranheza”. Essa situação não é rara, já que as questões de gênero se mostram fundamentais na condução das escolhas reprodutivas de adolescentes, particularmente no momento da primeira relação sexual ${ }^{(3)}$. Como exemplifica a oitava entrevistada, ao declarar que as colegas cedem às pressões a fim de manterem seus relacionamentos, são os garotos que impõem o início da vida sexual, com suporte em um contexto favorável, no qual as próprias meninas excluem aquelas que não se submetem ao sistema. Esse grau de submissão em adolescentes em fase de estruturação da personalidade é bastante perigoso e não oferece um bom prognóstico para os seus relacionamentos futuros.

Assim, percebe-se que, se o modelo dito conservador mantém a mulher em estado de submissão relativamente ao "macho dominante", também o comportamento aparentemente progressista oculta, por trás do véu de liberalismo, a submissão feminina em relação aos desejos masculinos, perpetuando as relações de gênero hierárquicas e as vulnerabilidades delas decorrentes.

Mais uma vez, a família entra no circuito das questões de gênero, colaborando para o estabelecimento de vulnerabilidades. Ao afirmar ter uma amiga que esconde da mãe e não tem dinheiro para comprar o contraceptivo, a entrevistada expõe que, embora o início da vida sexual da menina seja cobrado por seus pares, ele não é tolerado pelos pais, ao contrário do que ocorre com os rapazes. A família deixa de pautar esse assunto com a garota por, muitas vezes, não percebê-la como uma mulher que pode iniciar a vida sexual, e isso a coloca em situação de vulnerabilidade ${ }^{(26,27)}$. A família influencia no comportamento, reproduzindo a condição de que os garotos devem ser sexualmente capazes e potentes, e a garota deve ser passiva, dependente e sensível.

Com relação às pílulas anticoncepcionais, as mulheres podem escolher o momento para engravidar. Em contrapartida, aumentou a responsabilidade feminina sobre eventos reprodutivos. Como exprimiu um adolescente, "mesmo com toda informação, ainda tem gente que faz burrada, que é engravidar muito nova. Perde os estudos, perde tudo" (A4), refletindo a responsabilização cultural e social das mulheres pela reprodução. Trata-se de uma atualização do determinismo dos papéis sociais baseados no gênero, o que contribui para a perpetuação das vulnerabilidades relacionadas a essas questões.
Outra adolescente, percebendo as diferenças estabelecidas entre os gêneros, indagou: "Menina eu sei que sofre. Será que os meninos não sofrem nada? Será que tudo é fácil'? (A8). Esse questionamento transcende a questão fisiológica. As relações desiguais são vistas em diferentes âmbitos das pessoas e da coletividade, inclusive na sexualidade e na vulnerabilidade a que os gêneros estão $\operatorname{expostos}^{(5)}$. É na adolescência que se elabora essa relação com o fenômeno da diferença, e o modo como esta se estabelece será crucial para determinar como as relações de gênero influenciarão o restante de suas vidas ${ }^{(28)}$.

Compreender o fenômeno da sexualidade nos adolescentes a partir das relações de gênero permite situálos no contexto social, o que implica ir além das questões biológicas e epidemiológicas ${ }^{(29)}$. Se as adolescentes são submissas no início de suas vidas sexuais, há grande possibilidade de o serem em seus relacionamentos futuros. É em decorrência do atual formato das relações de gênero desiguais que as mulheres se encontram em uma situação de grande vulnerabilidade em relação às diversas expressões de violências e às $\mathrm{DSTs}^{(21)}$.

Do mesmo modo, as percepções dos adolescentes sobre os papéis de gênero descortinam outra vulnerabilidade social: a homofobia.

\section{Preconceito ou tolerância: a identidade de gênero para os adolescentes}

Em referências a esta categoria, a identidade de gênero surge nos discursos dos meninos coadunando-se com os discursos que perpetuam preconceitos e vulnerabilidades.

"Sexualidade acho que tem a ver com ser homossexual ou ser heterossexual. Mas tem tanta marmota hoje em dia que é até dificil." (A4)

"Embora tenha muita gente que tem preconceito, eu, por exemplo, sou homem, sou macho, mas não tenho raiva nenhuma de quem não é. A vida é dele, o problema é dele, eu não me meto." (A7)

"No meu entender, 'sexualidade' é um termo que diferencia uma pessoa da outra, se um ser é macho ou é feminino, afeminado." (A10)

Embora os adolescentes neguem preconceito, não se percebe nos discursos aceitação, e sim tolerância. A expressão regional "marmota", que significa coisa fora de ordem ou bagunçada, foi utilizada como referência pejorativa a identidades sexuais diferentes das consideradas normais pelo adolescente. Quando um dos participantes acentua que "o problema é dele" (do outro), demonstra reconhecer a homoafetividade como um problema a ser solucionado. Quando enfatiza que é homem, reproduz os padrões de comportamento que a sociedade incorporou 
como normalidade. Quando o outro adolescente classifica as pessoas entre "macho" e "afeminado", demonstra ter incorporado os estereótipos clássicos relacionados à sexualidade masculina e que eternizam preconceitos e violências.

É interessante observar que as referências à homoafetividade surgiram espontaneamente nos discursos dos meninos, não aparecendo nos discursos das meninas. Por que isso ocorre? $\mathrm{Na}$ adolescência, período crítico do desenvolvimento da sexualidade, geralmente há o primeiro contato sexual com envolvimento genital. Essa intimidade corporal e emocional acontece mais comumente com alguém do sexo oposto. É possível, porém, ocorrer manifestações sexuais entre pessoas do mesmo sexo que estão se descobrindo, experimentando o que é ser homem e/ou ser mulher. São meninas que trocam confidências, carinhos com suas amigas, e meninos que buscam parceiros para brincadeiras e vivências. Trata-se de uma fase de experimentação que contribui para a constituição da identidade sexual futura ${ }^{(30)}$.

Os meninos, entretanto, sofrem desde cedo com exigências de afirmação de sua masculinidade ${ }^{(5)}$. Desse modo, as questões relativas à escolha de objeto sexual são motivo de angústia para eles. Embora a percepção positiva da homossexualidade tenha aumentado gradualmente, as percepções negativas ainda predominam. O discurso dominante a associa ao pecado, crime, perversão, doença, anormalidade. $\mathrm{Na}$ área da saúde, a temática que se destaca é a questão da Síndrome da Imunodeficiência Adquirida (AIDS) e da vulnerabilidade ao Vírus da Imunodeficiência Humana (HIV) relacionadas à homossexualidade masculina ${ }^{(4)}$.

Essa realidade é demonstrada nos discursos dos adolescentes, os quais refletem o preconceito velado, bastante comum nos tempos atuais. Percebe-se claramente a necessidade dos adolescentes de se firmarem como "homens" - viris, fortes, "machos". Apesar das mudanças culturais, o estereótipo do "macho nordestino" ainda persiste, apenas é atualizado, adquirindo uma nova roupagem, de aparente tolerância em relação aos "afeminados", mas continuando o ciclo de preconceito e violência que o caracteriza.

\section{CONSIDERAÇÕES FINAIS}

Os adolescentes trouxeram elementos discursivos que refletem os tabus que os cercam sobre a sexualidade e a marcada exigência de um comportamento estereotipado segundo os padrões regionais, embora esses modelos tenham sido atualizados ante o contexto da sociedade de consumo do mundo globalizado. A necessidade de autoafirmação masculina, a submissão feminina ante os desejos masculinos, a responsabilidade da mulher pela reprodução e o preconceito velado em relação à homossexualidade foram comuns nos discursos dos participantes. Esses padrões espelham um modelo hierárquico de relação de gênero que expõe homens e mulheres a situações de vulnerabilidades eternizadas por fatores socioculturais e que iniciam sua afirmação no período da adolescência.

Se, no entanto, a mulher é colocada em situação de vulnerabilidade devido à hierarquização das relações de gênero, o homem também se torna vulnerável na medida em que assume o papel de "macho dominante", não podendo demonstrar socialmente suas fragilidades, o que os leva a procurar tardiamente os serviços de saúde e induz as políticas de saúde a negligenciarem a saúde masculina.

Para superar as vulnerabilidades a que homens e mulheres estão expostos, torna-se cada vez mais necessário superar a visão de uma "onipotência" masculina. Como, porém, transcender essa percepção culturalmente instituída, ainda mais em uma região onde ser "macho" é uma exigência social? É fato que os estereótipos masculinos associados à força, poder, agressividade e capacidade de domínio surgem nos discursos dos adolescentes como uma extensão dos discursos que os antecederam.

Esses adolescentes reproduzem a realidade que conhecem, que se descortina diariamente diante de seus olhos, em sua realidade familiar e social. Trabalhar as questões de gênero e suas relações com esse grupo, mediante a exposição de novas perspectivas, pode ser crucial para uma mudança de atitudes e convicções, retirando essa nova geração do círculo vicioso instituído em estereótipos predefinidos dos papéis de macho e fêmea.

Finalmente, cabe ressaltar que uma limitação deste estudo é que, por seu corte qualitativo, os resultados não são generalizáveis para o conjunto de adolescentes do contexto investigado, embora os dados apresentados estejam em consonância com a literatura a respeito.

\section{REFERÊNCIAS}

1. Foucault M. The history of sexuality: the will to knowledge. London: Penguin Books; 2006. p. 176.

2. Lindau ST, Gavrilova N. Sex, health, and years of sexually active life gained due to good health: evidence from two US populations based cross sectional surveys of ageing. BMJ. 2010;340:c810

3. Borges ALV. Relações de gênero e iniciação sexual de mulheres adolescentes. Rev Esc Enferm USP. 2007;41(4):597-604.

4. Feng Y, Lou C, Gao E, Tu X, Cheng Y, Emerson MR et al. Adolescents' and young adults' perception of homosexuality and related factors in three Asian cities. J Adolesc Health. 2012;50(3 Suppl):S52-60 
5. Torres CA, Beserra EP, Barroso MGT. Relações de gênero e vulnerabilidade às doenças sexualmente transmissíveis: percepções sobre a sexualidade dos adolescentes. Esc Anna Nery Rev Enferm. 2007;11(2):296-302.

6. Scott JW. Gênero: uma categoria útil de análise histórica. Educação Realidade. 1995;20(2):71-99.

7. Departamento Intersindical de Estatística e Estudos Socioeconômicos - DIEESE. Anuário das mulheres brasileiras [Internet]. São Paulo: DIEESE, 2011 [acesso em 2015 Abr 10]. Disponível em: http://www.dieese. org.br/anuario/anuarioMulheresBrasileiras2011.pdf.

8. Garcia LP, Freitas LRS, Silva GDM, Höfelmann DA. Estimativas corrigidas de feminicídios no Brasil, 2009 a 2011. Rev Panam Salud Publica. 2015;37(4/5):251-7.

9. Foucault M. Microfísica do poder. $13^{\mathrm{a}}$ ed. Rio de Janeiro: Graal; 1998.

10. Fontanella BJB, Luchesi BM., Saidel MGB, Ricas J, Turato ER, Melo DG. Amostragem em pesquisas qualitativas: proposta de procedimentos para constatar saturação teórica. Cad Saúde Pública. 2011;27(2):38994.

11. Veiga-Neto A. Michel Foucault e os estudos culturais. In: Costa MV, organizador. Estudos culturais em educação: mídia, arquitetura, brinquedo, biologia, literatura, cinema. Porto Alegre: UFRGS; 2000. p. 3772.

12. Butler J. Gender trouble: feminism and the subversion of identity. Nova York: Routledge; 1990. p. 172.

13. Denzin N. Performance ethnography: critical pedagogy and the politics of culture. Thousand Oaks: Sage; 2003.

14. Hall S. The work of representation. In: Hall S, organização. Representation: cultural representation and cultural signifying practices. London: Sage/Open University; 1997. p. 1-47.

15. Orlandi E. A análise de discurso e seus entremeios: notas para a sua história no Brasil. Cad Estudos Linguísticos. 2002;42:21-40.

16. Orlandi E. Discurso, imaginário social e conhecimento. Em aberto. 1994;61(14):53-9.

17. Orlandi E. Análise do discurso: princípios e procedimentos. Campinas: Pontes; 2009.

18. Mussalin F. Análise do discurso. In: Mussalin F, Bentes AC. Introdução à linguística: domínio e fronteiras. $3^{\mathrm{a}}$ ed. São Paulo: Cortez; 2003. v. 2. p. 13-52.

19. Pêcheux M. Só há causa daquilo que lhe falha ou o inverno político francês: início de uma retificação.
In: Pêcheux M. Semântica e discurso: uma crítica à afirmação do óbvio. Campinas: UNICAMP; 1988. p. 293-307.

20. Pêcheux M. Análise automática do discurso. In: Gadet F, Hak T. Uma introdução à obra de Michel Pêcheux. $4^{\mathrm{a}}$ ed. Campinas: UNICAMP; 2010. p. 59-158.

21. Hindin MJ, Muntifering CJ. Women's autonomy and timing of most recent sexual intercourse in SubSaharan Africa: a multi-country analysis. J Sex Res. 2011;48(6):511-9.

22. Lee-Rife S. Women's empowerment and reproductive experiences over the life course. Social Soc Sci Med. 2010;71(3):634-42.

23. Traverso-Yépez MA, Pinheiro VS. Socialização de gênero e adolescência. Estudos Feministas. 2005;13(1):147-62.

24. Almeida AFF, Hardy E. Vulnerabilidade de gênero para a paternidade em homens adolescentes. Rev Saúde Pública. 2007;41(4):565-72.

25. Braz M. A construção da subjetividade masculina e seu impacto sobre a saúde do homem: reflexão bioética sobre justiça distributiva. Ciênc Saúde Coletiva. 2005;10(1):97-104.

26. Beckett MK, Elliott MN, Martino S, Kanouse DE, Corona R, Klein DJ et al. Timing of parent and child communication about sexuality relative to children's sexual behaviors. Pediatrics. 2010;125(1):34-42.

27. Deptula DP, Henry DB, Schoeny ME. How can parents make a difference? Longitudinal associations with adolescent sexual behavior. J Fam Psychol. 2010;24(6):731-9.

28. Denny KE. Gender in context, content and approach comparing gender messages in girl scout and boy scout handbooks. Gend Soc. 2011;25(1):27-47.

29. Ott MA. Examining the development and sexual behavior of adolescent males. J Adolesc Health. 2010;46(4 Suppl):S3-11.

30. Taquette SR. Interseccionalidade de gênero, classe e raça e vulnerabilidade de adolescentes negras às DST/ AIDS. Saúde Soc. 2010;19(Supl 2):51-62.

\section{Endereço para correspondência:}

Aline Veras Morais Brilhante

Universidade de Fortaleza - UNIFOR

Programa de Pós-graduação em Saúde Coletiva

Av. Washington Soares, 1321 - Sala S1

Bairro: Edson Queiroz

CEP 60811-905 - Fortaleza - CE - Brasil.

E-mail: alineveras01@yahoo.com.br 